\title{
Twin peaks, extramarital conceptions, and virgin births: is there a connection?
}

\author{
M Murphy, V Seagroatt
}

\begin{abstract}
The trends in British twin and higher multiple birth rates inside and outside marriage from 1938 to 1989 were reviewed for evidence of the probable impact of the use of ovulatory stimulants.

After adjustment for maternal age monozygotic twin rates within marriage rose to a significant excess (of $12 \%$ ) over those outside during the last two decades; a similar increase of higher multiple births within marriage to a significant excess (of $50 \%$ ) over those outside was also seen for 1980-9. The dizygotic twin rate within marriage exceeded that outside in 1989 for only the second time in $\mathbf{5 0}$ years, as the difference in rates narrowed in the last decade.

It is concluded that ovulation induction and techniques of assisted conception are apparently more available to the married, with a stronger effect on higher multiple birth rates than on dizygotic twin rates. Monozygotic twin trends support the suggestion that part of the infertility treatment regimen also promotes zygote splitting.
\end{abstract}

Department of Public Health and Primary Care, Radcliffe Infirmary, Oxford OX2 6HE M Murphy

Unit of Clinical Epidemiology, University of Oxford

$\mathrm{V}$ Seagroatt

Correspondence to:

Dr Murphy.

Accepted 14 October 1991

The profound fall in dizygotic twinning rates observed since the $1950 \mathrm{~s} / 60 \mathrm{~s}$ in many developed countries taught us little about the factors that caused the decline, ${ }^{1}$ but the recent upturn may reveal more. ${ }^{2}$ It has been suggested that the movement of dizygotic twinning rates may, among other things, reflect change in the average fecundability of the population reproducing. ${ }^{3-5}$ However, it may be the treatment of infertility with ovulation induction drugs that

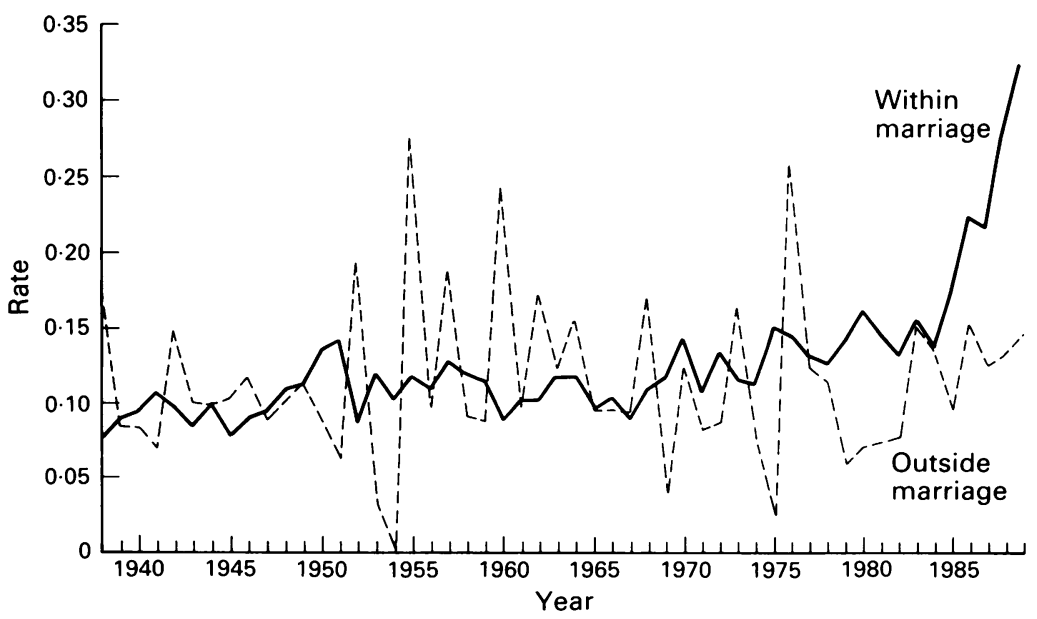

Figure 1 Age standardised triplet and higher rate of multiple births/1000 maternities: England and Wales 1938-89. is currently most influencing the twinning rate and arresting the previous fall, so that 'natural' reproductive ability might still be in decline for reasons that remain unexplained. ${ }^{6} 7$ Recently attention has focused on the availability of infertility treatment/assisted conception techniques for single women. ${ }^{8}$ If such treatments are differentially available by marital status, in Britain, the situation constitutes a 'natural experiment' that may assist interpretation of the changing patterns of dizygotic twinning in particular. We therefore compared statistics on twinning and higher multiple birth rates within and outside marriage for evidence of discrepant trends, as the rates outside marriage may more accurately reflect any underlying trend in fecundability on which is superimposed the effects of infertility treatment.

\section{Methods}

Total maternities, numbers of live and stillborn twins by sex combination, and numbers of triplet and higher order births for England and Wales were obtained by mother's age and marital status from the Office of Population Censuses and Surveys (OPCS) FM1 fertility series publications from 1974-88, except for the year 1981, when the registrars' dispute meant multiple birth statistics are inaccurate, and for 1938-73 from the Registrar General's annual reports. OPCS also made available similar data for 1989 and for twins and maternities where the birth was outside marriage but either jointly registered by both parents or by the mother alone between 1974-89. For Scotland data for twins from 1952-89 were obtained from the Registrar General's reports and directly from the General Registry Office (Scotland). These rates were age standardised and the proportions of twins which were monozygotic or dizygotic were estimated using Weinberg's rule.

Results

Figure 1 shows triplet and higher multiple birth rates inside and outside marriage from 1938-89, indirectly age standardised using average rates for all women over the whole period as standard. The rates within marriage were initially constant but have increased over the last 20 years, accelerating rapidly in the $1980 \mathrm{~s}$, whereas the rates outside marriage do not show this increase.

Figure 2 shows total, monozygotic, and dizygotic twinning rates within and outside marriage from 1938-89 in England and Wales, indirectly age standardised using the maternal age specific unlike sexed and total twinning 
rates among all women for 1970 as standard. Overall, the upturn in twinning rates in the recent past is due to the reversal of the downward trend in dizygotic and the small but longstanding increase in monozygotic twin rates. Within and outside marriage monozygotic twin

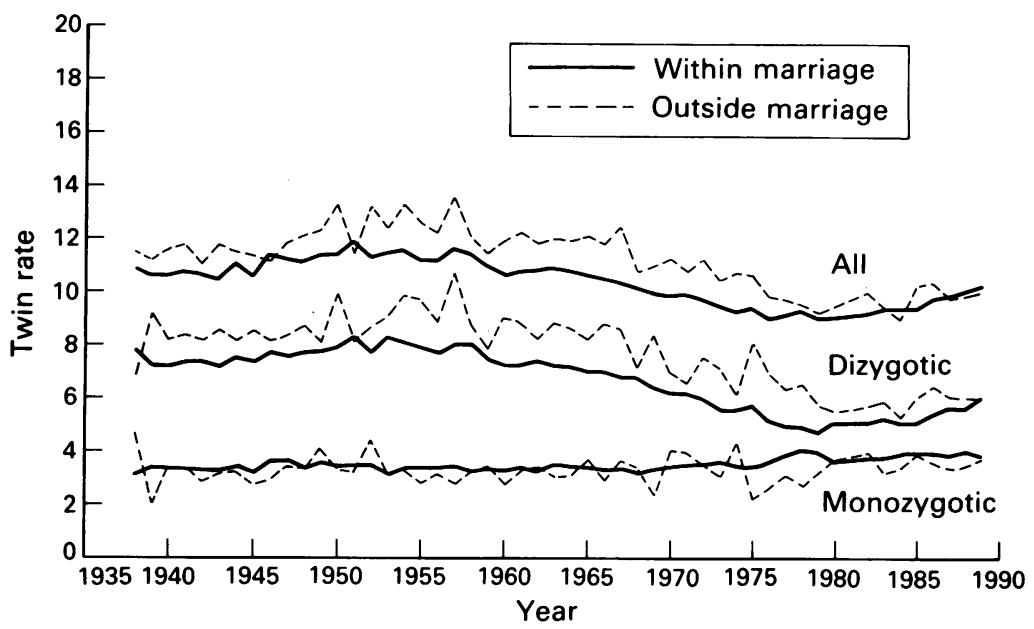

Figure 2 Age standardised twin rates/1000 maternities: England and Wales 1938-89.

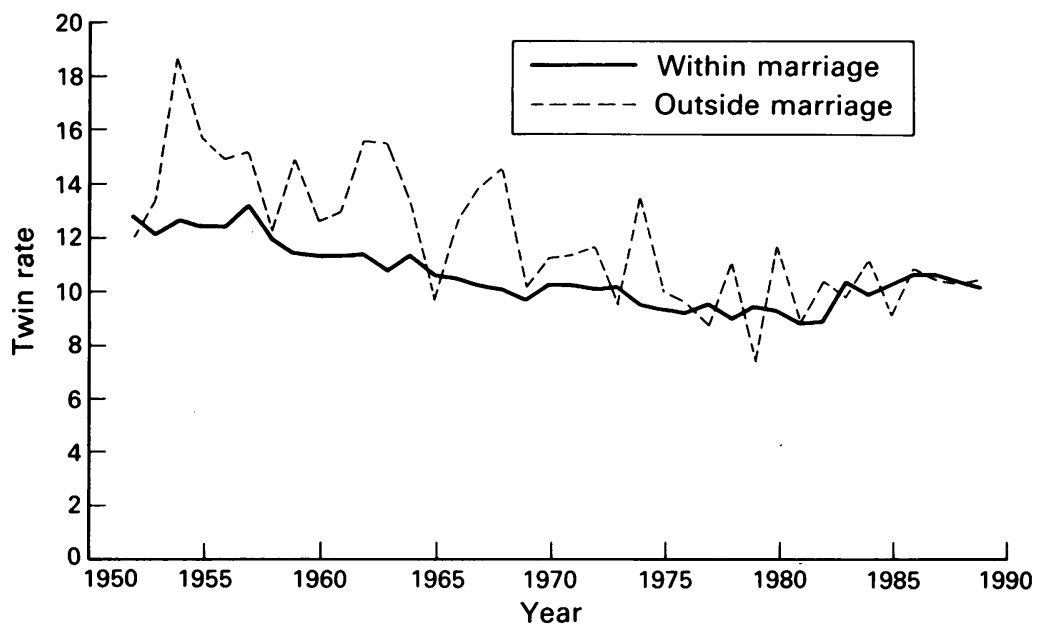

Figure 3 Age standardised twin rates/1000 maternities: Scotland 1952-89.

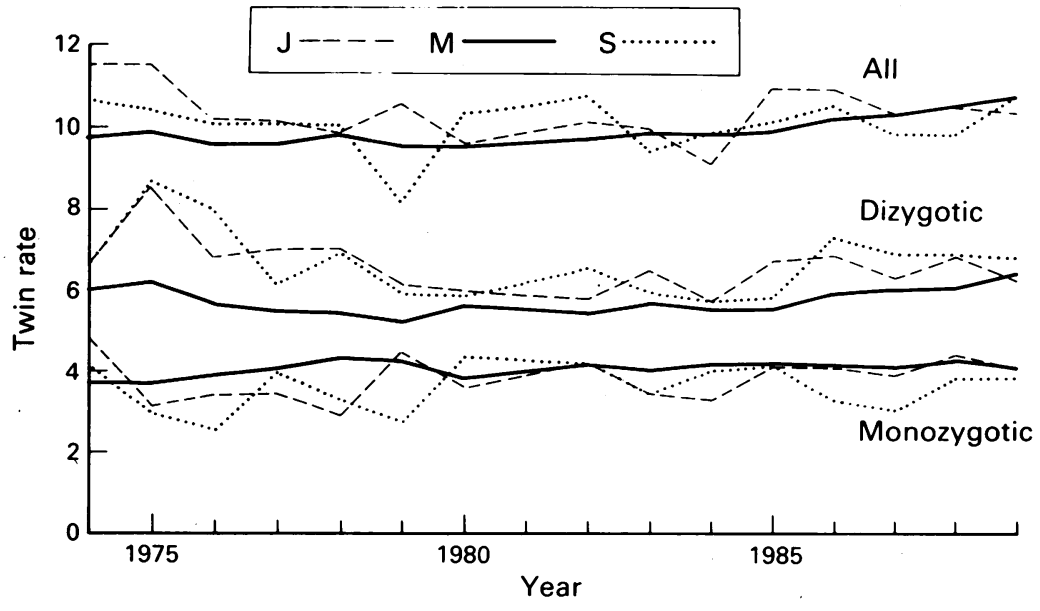

Figure 4. Age standardised twin rates 1000 maternities for all twins, monozygotic and dizygotic twins, within marriage $(M)$ and sole $(S)$ or jointly $(\mathcal{F})$ registered maternities outside marriage: England and Wales 1974-89. rates share a similar upward trajectory until the 1970s when a greater increase was seen within marriage (as for the higher order births). Dizygotic rates were consistently higher outside marriage until 1989 when they reversed. This convergence was due to the rates increasing within marriage. Figure 3 shows that Scotland has had similar but generally higher total twinning rates than England and Wales (age adjusted to the same standard) and that the rates fell there more dramatically before increasing again.

Figure 4 shows the total, dizygotic, and monozygotic twinning rates from $1974-89$ for births within marriage, births outside marriage jointly registered by both parents, and those registered solely by the mother, indirectly age standardised using the average rates for al women over the whole period as standard. The proportion of births outside marriage has risen steeply over the last decade, largely accounted for by the increase in births jointly registered by both parents. In 1989, $75 \%$ of births outside marriage were jointly registered and $75 \%$ of these parents gave the same usual address, so that births outside marriage increasingly resemble those within. The rates for joint and solely registered dizygotic (and all) twins were similar, and both were higher than the rates within marriage. For monozygotic twins the jointly registered rates lay between those for the married and the solely registered. Significant differences between the sole and jointly registered twin rates were found only for the monozygotic, $\left(\chi^{2}=5 \cdot 3 ; \mathrm{df}=1, \mathrm{p}<0 \cdot 05\right)$.

The table shows how the relationship between dizygotic, monozygotic, total twin, and higher order birth rates changed within and outside marriage over the five decades. For dizygotic twins the difference between the rates within and outside marriage was narrower in 1980-9 than over the previous 40 years. Monozygotic twin rates within marriage have become significantly greater than those outside over the last two decades, a pattern which is also evident in the period 1980-9 for higher multiple births.

\section{Discussion}

As far as can be judged, the evidence provided by births (which exclude 'vanishing twins', pregnancy miscarriage, and therapeutic abortion) should be taken at face value as an indicator of changing patterns of multiple pregnancies.

The steady increase in higher multiple births within marriage, dating from the early 1970 s, seems likely to have been due to rare consequences of the use of ovulation induction agents, followed by a much accelerated increase in the mid-1980s as a more common result of the use of in vitro fertilisation and related techniques. The absolute number of these births remains small so estimation of zygosity is not warranted. The number outside marriage is so small that no definitive conclusions as to the trends can be drawn, though it would seem they have been largely unaffected by the spreading use of techniques of assisted conception.

The phenomenon that dizygotic twinning 
Age standardised rates 1000 maternities for twins and higher order births by marital state and time period. Odds ratios (OR) are adjusted for age and are given with their $95 \%$ confidence intervals $(C I)$

\begin{tabular}{|c|c|c|c|c|c|c|c|c|c|c|c|c|c|}
\hline \multirow[t]{2}{*}{ Period } & \multirow{2}{*}{$\begin{array}{l}\text { Marital } \\
\text { status }\end{array}$} & \multicolumn{3}{|c|}{ Dizygotic twins } & \multicolumn{3}{|c|}{ Monozygotic twins } & \multicolumn{3}{|c|}{ All twins } & \multicolumn{3}{|c|}{ Higher order births } \\
\hline & & Rate & OR & $95 \% C I$ & Rate & $O R$ & $95 \% C I$ & Rate & $O R$ & $95 \% C I$ & Rate & $O R$ & $95 \% C I$ \\
\hline $\begin{array}{l}1938-49 \\
1950-59 \\
1960-69 \\
1970-79 \\
1980-89\end{array}$ & $\begin{array}{l}\text { Married } \\
\text { Unmarried } \\
\text { Married } \\
\text { Unmarried } \\
\text { Married } \\
\text { Unmarried } \\
\text { Married } \\
\text { Unmarried } \\
\text { Married } \\
\text { Unmarried }\end{array}$ & $\begin{array}{l}8 \cdot 0 \\
8 \cdot 9 \\
8 \cdot 6 \\
9 \cdot 9 \\
7 \cdot 8 \\
9 \cdot 4 \\
6 \cdot 3 \\
7 \cdot 7 \\
6 \cdot 1 \\
6 \cdot 9\end{array}$ & $\begin{array}{l}1 \cdot 0 \\
1 \cdot 13^{*} \\
1 \cdot 0 \\
1 \cdot 16^{*} \\
1 \cdot 0 \\
1 \cdot 21^{*} \\
1 \cdot 0 \\
1 \cdot 20^{*} \\
1 \cdot 0 \\
1 \cdot 12^{*}\end{array}$ & $\begin{array}{l}1.09 \text { to } 1.16 \\
1.12 \text { to } 1.20 \\
1.17 \text { to } 1.25 \\
1.16 \text { to } 1.25 \\
1.09 \text { to } 1.15\end{array}$ & $\begin{array}{l}3 \cdot 5 \\
3 \cdot 4 \\
3 \cdot 5 \\
3 \cdot 5 \\
3 \cdot 6 \\
3 \cdot 5 \\
4 \cdot 0 \\
3 \cdot 6 \\
4 \cdot 3 \\
3 \cdot 8\end{array}$ & $\begin{array}{l}1.0 \\
0.98 \\
1.0 \\
0.99 \\
1.0 \\
0.96 \\
1.0 \\
0.94^{*} \\
1.0 \\
0.92^{*}\end{array}$ & $\begin{array}{l}0.93 \text { to } 1.04 \\
0.93 \text { to } 1.05 \\
0.91 \text { to } 1.00 \\
0.89 \text { to } 0.98 \\
0.89 \text { to } 0.95\end{array}$ & $\begin{array}{l}11 \cdot 5 \\
12 \cdot 2 \\
12 \cdot 2 \\
13 \cdot 3 \\
11 \cdot 4 \\
12 \cdot 7 \\
10 \cdot 3 \\
11 \cdot 3 \\
10 \cdot 4 \\
10 \cdot 8\end{array}$ & $\begin{array}{l}1 \cdot 0 \\
1 \cdot 06^{*} \\
1 \cdot 0 \\
1 \cdot 10^{*} \\
1 \cdot 0 \\
1 \cdot 12^{*} \\
1 \cdot 0 \\
1.08^{*} \\
1 \cdot 0 \\
1 \cdot 03^{*}\end{array}$ & $\begin{array}{l}1.03 \text { to } 1.09 \\
1.07 \text { to } 1.14 \\
1.09 \text { to } 1.15 \\
1.05 \text { to } 1.12 \\
1.01 \text { to } 1.05\end{array}$ & $\begin{array}{l}0 \cdot 10 \\
0 \cdot 10 \\
0 \cdot 12 \\
0 \cdot 11 \\
0 \cdot 10 \\
0 \cdot 13 \\
0 \cdot 13 \\
0 \cdot 11 \\
0 \cdot 19 \\
0 \cdot 12\end{array}$ & $\begin{array}{l}1 \cdot 0 \\
1 \cdot 09 \\
1 \cdot 0 \\
0 \cdot 90 \\
1 \cdot 0 \\
1 \cdot 17 \\
1 \cdot 0 \\
0 \cdot 87 \\
1 \cdot 0 \\
0 \cdot 67^{*}\end{array}$ & $\begin{array}{l}0.81 \text { to } 1.48 \\
0.64 \text { to } 1.28 \\
0.89 \text { to } 1.53 \\
0.64 \text { to } 1.17 \\
0.54 \text { to } 0.83\end{array}$ \\
\hline
\end{tabular}

* Denotes OR significantly different from one; in each case they were significantly different at the $1 \%$ level.

rates outside marriage have always been higher than within, at all ages except the youngest, has been observed in a number of different countries. ${ }^{45}$ It has been interpreted as evidence that women prone to twins are also more fecundable, and hence more likely to become pregnant outside marriage with an accompanying higher twin rate. Thus one explanation for the declining dizygotic twin rate was that the advent of widespread oral contraceptive use masked high fecundability/twin proneness. Concomitant social changes, such as the decrease in completed family size, would tend to be associated with a decline in dizygotic twinning while others, such as postponement of the age at which childbearing is completed, would have had the opposite effect. These explanations may be inadequate however and the decrease in dizygotic twinning may have represented a worrying decline in natural fecundability, though secular fluctuations in the rate of twinning necessarily give rise to speculation about what is the natural background rate.

Social selective processes operate continuously so that cohorts of women reproducing will differ in various ways from the generations on either side, particularly when defined in terms of marriage. However, it seems unlikely that the recent convergence of dizygotic twin rates between married and unmarried reflects a differential alteration in the 'natural' propensity to twinning. Rather, the resurgence of dizygotic twinning is due to the increased risk of multiple births after ovulation induction. There is greater likelihood of use if married or intending to marry, though it is not completely clear that the proportion of twin births after use of these drugs would be alone sufficient to have reversed the decline in twinning. ${ }^{7}$ The absence of a difference in the trends in dizygotic twinning rates between the 'new' type of birth outside marriage (the birth jointly registered by both parents) and the 'old' type (the birth solely registered by the mother) may reflect a wider access to infertility treatment, irrespective of marital or partnership status, than we had imagined. It probably will not be possible to tell whether a reversal of natural fecundability also took place, but we can be sure that a birth registered by the mother alone, stereotypically a single parent, is no longer presumptive evidence that conception was unassisted by artificial means.

Of equal interest are trends in the rates of monozygotic twinning. Their long term small increase does not mirror the ups and downs of dizygotic twinning and hence it seems unlikely to be an artefact of the method of estimation of their numbers. From the mid-1970s onwards monozygotic twin rates within marriage started to exceed those outside. Very little is known to affect the risk of monozygotic twinning, except perhaps age, for which we adjusted, and the possibility that some component of the assisted conception process may influence zygote splitting. ${ }^{10}$ There may be evidence here from the increase in relation to marriage from the 1970s onwards of the higher multiple births (zygosity unknown) and monozygotic twins (zygosity estimated) that this may be so and it should be investigated further.

We would like to thank Penny Callaghan of the department of public health and primary care for typing the manuscript and Kate Hey of the Unit of Clinical Epidemiology for assistance with data preparation

The Unit of Clinical Epidemiology is funded by the Depart ment of Health.

1 Anonymous. Worldwide decline in dizygotic iwinning [Editorial]. BMF 1976; 1553 .

2 Botting B, Davies IM, Macfarlane A. Recent trends in the incidence of multiple births and their mortality. Arch $D$ is Child 1987;62:941-50.

3 Allen G. The twinning and fertility paradox. In: Gedda L, Parisi P, Nance WE, eds. Twin research 3. Part A: twin biology and multiple pregnancy. Progress in clinical and biological research. Vol 69A. New York: Alan R Liss, 1981: $1-13$.

4 James WH. Dizygotic twinning, marital stage and status and coital rates. Ann Hum Biol 1981;8:371-8.

5 Eriksson AW, Fellman J. Twinning and legitimacy. Hereditas 1967;57:395-402.

6 Botting B, Macfarlane AJ, Price FV, eds. Three, four and more. A study of triplet and higher order births. London: HMSO, 1990 .

7 Webster F, Elwood JM. A study of the influence of ovulation stimulants and oral contraception on twin births in England. Acta Genet Med Gemellol (Roma) 1985;34:105-8

8 Jennings S. Virgin birth syndrome. Lancet 1991;337:559-60. Allen G. Errors of Weinberg's difference method. In: Gedda L, Parisi P, Nance WE, eds. Twin research 3. Part A: twin biology and multiple pregnancy. Progress in clinical and biological research. Vol 69A. New York: Alan R Liss, 1981:71-4.

10 Derom C, Derom R, Vlietinck R, Van Den Berghe H, Thiery $M$. Increased monozygotic twinning rate after ovulation induction. Lancet 1987;i:1236-8. 